\title{
Arbor
}

\section{Hablar de Dios en la «aldea global». La palabra de la fe entre la posmodernidad y el reverso de la historia}

\section{Bruno Forte}

Arbor CLXXI, 676 (Abril), 677-688 pp.

¿Qué sentido tiene hablar de Dios hoy? ¿Cómo hablar de Dios en este mundo posmoderno? ¿Cómo hacerlo desde el «reverso de la historia»? ¿Cómo vivir frente a estos retos diferentes la fidelidad al mundo presente y la fidelidad al mundo que tiene que venir? El presente trabajo intenta dar respuesta a estos interrogantes en la «aldea global» que es nuestro mundo vinculado entre sí por los juegos del poder y por la red de las comunicaciones, Dos grandes contextos se dibujan y caracterizan a la actual situación histórica del cristianismo. Por un lado está el Norte occidental (europeo y americano) del planeta que ha vivido la parábola de la Ilustración y que entra ahora en las incertidumbres de la posmodernidad; por otro lado está el Sur de la tierra, el «reverso de la historia», el mundo de los pobres y de los oprimidos con la suma infinita de su dolor. La palabra de la fe debe mirar en esta doble dirección para hablar lo más posible el lenguaje del tiempo real; $y$ si son diversos los retos que recibe, no es diversa la tarea que le incumbe de una fidelidad única y doble al caminar del hombre y al acercarse de Dios, al éxodo humano y al adviento del Eterno.

«La Iglesia no se halla allí donde fracasa la capacidad humana, sino en el medio de la aldea»: estas palabras de Dietrich Bonhoeffer, escritas en un tiempo en que la conciencia creyente parecía experimentar el des- 
tierro y el silencio de Dios en la tragedia de la guerra y en los horrores de la Shoah, esbozan un programa, al que es justo atenerse también en otras circunstancias de la historia, si es que queremos dar una respuesta responsable a la pregunta: ¿Qué sentido tiene hablar de Dios hoy? La «aldea global», que es nuestro mundo vinculado entre sí por los juegos del poder y por la red de las comunicaciones, se muestra compleja a quien quiera proponer la palabra de la fe en medio de ella: dos grandes contextos se dibujan y caracterizan a la actual situación histórica del cristianismo. Por un lado está el Norte occidental (europeo y americano) del planeta que ha vivido la parábola de la Ilustración y que entra ahora en las incertidumbres de la posmodernidad; por otro lado está el Sur de la tierra, el «reverso de la historia», el mundo de los pobres y de los oprimidos con la suma infinita de su dolor. La palabra de la fe debe mirar en esta doble dirección para hablar lo más posible el lenguaje del tiempo real; y si son diversos los retos que recibe, no es diversa la tarea que le incumbe de una fidelidad única y doble al caminar del hombre y al acercarse de Dios, al éxodo humano y al adviento del Eterno. ¿Cómo hablar de Dios en este mundo post-moderno? ¿Cómo hacerlo desde el «reverso de la historia»? ¿Cómo vivir frente a estos retos diferentes la fidelidad al mundo presente y la fidelidad al mundo que tiene que venir?

\section{La teología en el mundo posmoderno}

a) La parábola del tiempo moderno puede describirse como el proceso del nacimiento y desarrollo del proyecto de emancipación de la razón ilustrada, a través de la dialéctica de la Ilustración, hasta el perfilarse de lo posmoderno. «Emancipación» es la palabra clave que caracteriza a toda la época que está bajo el signo de la Ilustración: ella expresa el sueño de la razón moderna de hacer que el hombre sea finalmente adulto, libre de hipotecas ultramundanas, capaz de querer y de ser objeto de su propia historia. En cuanto tal, la emancipación señala el proceso de autoliberación y de autoafirmación del hombre, tanto si se le toma individualmente como si se le entiende colectivamente en los dinamismos históricos del cambio revolucionario. En este sentido la celebración más alta del acto de la razón, que es la filosofía hegeliana, puede entenderse como la lectura refleja de la revolución francesa, como una especie de comentario especulativo de la transformación emancipatoria que se llevaba a cabo. Ya Kant, respondiendo a la pregunta: «QQué es la ilustración?», había afirmado: "La ilustración es la salida del hombre de su minoría de edad, que él ha hecho a sí mismo. La minoría de edad es la incapacidad de ser- 
virse del propio entendimiento sin la guía de otro. Y esta minoría de edad depende de sí mismo si su causa reside en la falta, no ya de inteligencia, sino de la decisión y del coraje de servirse de ella sin la guía de otro». «Sapere aude»: ¡ten la osadía de servirte de la razón! He aquí la divisa de la Ilustración, la fascinación y la grandeza del reto moderno: poner el mundo y la vida en manos del hombre, responsabilizar al sujeto personal y colectivo, provocándolo a que se haga libre y creador de su propia historia, para respirar a pleno pulmón el gusto por la veracidad y la crítica, es decir, por una libertad adulta y emancipada.

En el aspecto teológico la empresa se ha traducido tanto en el rechazo de la imagen de un Dios émulo del hombre, como en la reducción de todo Absoluto al quedar aprisionado dentro de los horizontes mundanos. Quizás nadie como Friedrich Nietzsche haya sabido expresar la grandeza y el carácter trágico de esta empresa en el aforismo del hombre loco, que en pleno día encendía una linterna y echaba a correr por la plaza gritando sin cesar: «ßBusco a Dios! ¡Busco a Dios!». Como allí había muchos que no creían en Dios, su grito provocó la hilaridad. El loco se precipitó en medio de ellos y los traspasó con su mirada gritando: «¿Dónde se ha ido Dios? Yo os lo voy a decir: ¡Nosotros lo hemos matado! ¡Vosotros y yo! ¡Todos nosotros somos sus asesinos!... ¡Dios ha muerto! ¡Y somos nosotros quienes le hemos dado muerte! ¿Cómo nos consolaremos nosotros, asesinos entre los asesinos?» (La gaya ciencia, Aforismo 125). La razón, al absorber a Dios, ha ahogado dentro de sí toda posible alteridad. Todo límite le resulta insoportable, todo confín es para ella una provocación a la superación. La ideología, en todas sus formas teóricas así como en todas sus realizaciones prácticas, es la expresión de este hambre y sed de totalidad. La emancipación se convierte en totalitarismo; el sueño de la razón se queda en algo incompleto y frustrado, precisamente cuando parecía que podía celebrarse su cumplimiento; la Ilustración, maestra de la sospecha, se hace sospechosa a sí misma.

La «dialéctica de la ilustración» es precisamente la denuncia de las presunciones y de los límites de la razón emancipadora. La crítica que se ha venido desarrollando podría recogerse en torno a las categorías de la culpa, de la muerte y del más allá. Si queda eliminado todo sujeto metahistórico, ¿quién tendrá la culpa de los fallos históricos? La defensa de los derechos soberanos de la razón emancipadora determina en ella la necesidad de crearse mecanismos de autojustificación; se señalan entonces otros sujetos sobre los cuales descargar la responsabilidad del fracaso, sujetos trascendentales -la naturaleza, el Espíritu con la necesidad de lo negativo requerida por su movimiento dialéctico, como sucede en la ideología burguesa- o sujetos históricamente determinables -los enemi- 
gos del proletariado, los capitalistas, como sucede en el marxismo-. Si para unos la historia de los vencidos y el mal que devasta la tierra son el precio inevitable del desarrollo, la otra cara del proceso del Espíritu, para otros todo se debe a las culpas históricas de la burguesía. La ideología liberal del progreso, como la ideología marxista de la revolución, acaban ambas revelándose incapaces de una autocrítica liberadora; al buscar otros sujetos a los que imputar la historia de la culpa, para reservarse a sí mismas la historia del éxito, ponen de manifiesto los límites de la razón emancipadora, su incapacidad radical para conciliar las contradicciones de lo real. El sufrimiento de los vencidos denuncia cómo la historia de la emancipación puede resolverse, y de hecho se ha resuelto, demasiadas veces, en el triunfo de la violencia de los vencedores.

Si frente al fracaso la razón moderna reacciona con la autojustificación, frente al compromiso del presente tiende a una lectura solar, sin sombras ni ausencias. En relación con esta desconfianza de la Ilustración frente a la noche, cuando «todas las vacas parecen negras» (Hegel), se perfila la exigencia de restituir al hombre la muerte; la conciencia ilustrada produce una «filosofía sin la muerte». La voluntad de totalidad se traduce en una especie de presencia plena que lo reduce todo a uno mismo y que asegura siempre una explicación razonada de la ausencia. Es verdad que el mal y la muerte constituyen una dificultad, pero esta dificultad vuelve a entrar en el orden como un momento negativo necesario, que no se opone a la vida del Espíritu, sino que constituye una etapa o un precio pagado a la causa de la revolución para el futuro de todos. En la lucidez omnicomprensiva del pensamiento emancipado se ha producido sin embargo un resquebrajamiento: se descubre la presencia inquietante de la "flor negra» (Hegel), metáfora de los espacios de realidad no aclarados por la presencia ni por la plenitud. Encontrar de nuevo el valor y la dignidad de la muerte, redescubrir el sentido de la interrupción y el peso de la ausencia significa ciertamente renunciar al sueño emancipador de totalidad, pero significa también respetar la verdad de la vida, con todas las interrupciones que se oponen a la pretensión ilustrada de un cumplimiento a toda costa. En este retorno de la muerte, la crítica a la Ilustración coincide con la que se dirige a todo sistema cerrado, presuntuosamente exhaustivo y completo, en favor de la realidad, en la que la noche, la quietud y el silencio no representan un papel menor que la luz del día, el movimiento o la palabra.

Finalmente, el sentido del más allá revela el cerrazón de la razón frente a lo que es verdaderamente nuevo, extraño y sorprendente para nosotros. En la presunción de la totalidad no queda espacio para el futuro; el «domingo de la vida» de la ideología acaba siendo una especie de 
«viernes santo del porvenir»; donde se ha alcanzado el vértice, no queda espacio para un cumplimiento ulterior, no existe disponibilidad para el asombro de la novedad. A la Ilustración en su versión burguesa le falta la esperanza porque donde la posesión lo es todo, no queda espacio para el éxodo; en su versión revolucionaria le falta la fantasía, porque la dictadura del proletariado se convierte en una rendición ante el presente $o$, todo lo más, en una deducción del futuro a partir del mismo. La razón emancipadora saborea las cebollas de Egipto: «El verdadero destierro de Israel en Egipto consistió en que los hebreos habían aprendido a soportarlo» (Martin Buber). El aburrimiento se extiende sobre todas las cosas: «Es como en un eclipse parcial de sol: todo parece extrañamente gris, y los pájaros no cantan o no cantan igual. Luego algo pasa. El ser trascendente es débil» (Ernst Bloch).

b) Frente a la crisis de la Ilustración se perfila la incertidumbre de la condición posmoderna. Se advierte con nueva seriedad el peso de la pregunta de Hölderlin: «¿De qué sirven los poetas en el tiempo de la pobreza?». Donde ha fracasado la razón totalizante, en el tiempo de una nueva pobreza respecto a la presunción de la posesión, se perfila la nostalgia de una palabra que evoque y no aprisione, que rompa el cerco de la presencia y abra al gusto y al valor de la ausencia. La totalidad cede su lugar al fragmento; la división y la separación parecen reinar en donde antes todo era orden y unidad; todo se hace fluido, discontinuo, interrumpido. Se da un adiós a las certezas para navegar hacia lo desconocido. Este adiós, este largo adiós es la condición posmoderna: es un tiempo de pensamiento débil, de aventuras de la diferencia, de crisis de la ideología. En su rechazo crítico de la Ilustración esta mentalidad no es muchas veces más que su forma invertida, un pensamiento de negación y de ruptura en donde aquella era pensamiento de afirmación y de conciliación; al conocimiento solar se le opone el amor a las tinieblas; al sentido de la posesión y de la consistencia, la «insoportable levedad del ser» (M. Kundera). Y es precisamente en este ser «antipensamiento» donde reside el riesgo de lo posmoderno de convertirse en una mera continuación dentro del signo de lo contrario de lo que intenta abandonar. La sed de totalidad de la razón emancipadora puede pasar a ser una nueva totalidad, la de lo negativo, que abarca todas las cosas. ¿Acaso el mismo nombre de posmoderno no esconde el peligro sutil, descrito admirablemente por aquella frase de Kundera: «La luz rojiza del atardecer lo ilumina todo con el hechizo de la nostalgia, incluso lo guillotina?»

Por eso mismo se va dibujando en la búsqueda de lo posmodemo una nueva figura: el totalmente Otro. Se expresa así el límite infranqueable de la razón, eso de lo que ella no puede decir qué es, aunque no tiene más re- 
medio que reconocer que es. La única manera de escapar de la presunción de la razón moderna es confesar una alteridad que rompa el dominio omnicomprensivo del sujeto y se le ofrezca como origen sin origen y fin sin fin, Otro indeducible de todo cuanto está a nuestra disposición e imposible de resolver en todo lo que nos es conocido. De esta alteridad es huella «el rostro del otro» (Emmanuel Lévinas), que rompe con su sola presencia todo imperialismo del sujeto, para afirmar -en la desnudez de su ofrecimiento en unos rasgos a veces muy pobres e insignificantes- la dignidad y la consistencia de la diferencia, irreducible a la identidad. La percepción de la alteridad radical en la epifanía del rostro del otro puede interpretarse como descubrimiento de un principio de heteronomía: nos descubrimos llamados a consentir con una anterioridad que no fundamos nosotros, aun cuando podamos situarnos respecto a ella. Una metáfora poderosa de esta alteridad es el «Ángel necesario» (Massimo Cacciari): «Yo soy el Ángel de la realidad, vislumbrado un instante en el umbral... Yo soy el Ángel necesario de la tierra, porque el que me ve, ve de nuevo la tierra, libre de los cepos de la mente, dura, terca, y el que me escucha, escucha cómo se eleva su canto monótono con una líquida lentitud y cómo aflora en sílabas de agua» (W. Stevens). El Ángel es testigo del misterio en cuanto misterio, trasmite lo invisible en cuanto invisible, sin «traicionarlo» por los sentidos. Entonces es necesario luchar con el Ángel, para que la tierra y las cosas se nos confíen en su verdad profunda; y este luchar con lo inefable es ya invocación. Donde ésta falta, donde son mayores el rechazo y la presunción, no se da ningún éxodo y ningún adviento...

c) En el medio de esta aldea posmoderna, salida de las aventuras de la emancipación oscilando entre el hechizo de una pura negatividad, herencia dialéctica de la ilustración, y el reconocimiento del Otro, es donde viene a situarse hoy la teología cristiana en el Norte del mundo, una teología que no es extraña a las vicisitudes que acabamos de describir. A una teología moderna, liberal y progresista, hechizada por la seducción del proyecto emancipatorio y dispuesta a identificar el evangelio de la liberación con el sueño de la emancipación, el giro dialéctico de Karl Barth ha opuesto precisamente un retorno a la "viva vox evangelii», a la narración santa de la salvación, en donde se realiza la llegada de Aquél que es totalmente Otro. Al riesgo presente en esta teología dialéctica de un "positivismo de la revelación», que salta simplemente sobre las exigencias de la subjetividad, el «giro antropológico» de la teología contemporánea ha opuesto el proyecto de un reflexión existencial, que apunta al encuentro entre el hombre vivo y el Dios vivo. Entre estas dos actitudes, cuyo mayor riesgo consiste respectivamente en celebrar la gloria de Dios a costa de la muerte del hombre o en celebrar la gloria del hombre a costa de la 
muerte de Dios, la palabra de la fe ha buscado una síntesis superior: en el común rechazo del «Deus mortuus» de la razón liberal y del «Deus otiosus» de la escolástica decadente, la parábola del siglo XIX se ha ido abriendo a una teología de la narración y de la analogía, dirigida a evocar lo inefable en el respeto a su inefabilidad y al mismo tiempo a hacerse cargo de las limitaciones y de las esperanzas producidas por la razón moderna y por las aventuras de la diferencia.

Respecto a la Ilustración, a esta teología le gustaría ofrecerse como un pensamiento débil, que renuncia en principio a la totalidad omnicomprensiva de un sistema, producido por la razón emancipadora; respecto a la posmodemidad afirma la necesidad del Presupuesto inefable, al que se acerca con temor y temblor en compañía de la tradición memorante-narrativa de la fe, y al que se abre según una escucha del adviento, que respeta la ulterioridad del Misterio. A esta teología, para que sea significativa y liberadora, no se le pide que lo diga todo o que lo explique todo; si lo hiciera, sería un producto más de la ideología moderna. Tampoco se le pide que calle, cayendo así en la insignificancia más completa. Se le pide que recuerde el Origen, haciendo memoria de él según las narraciones sagradas de la fe; se le pide que señale la Patria, vislumbrada en la promesa, pero no poseída aún; se le pide que inquiete al presente, denunciando sus ídolos, pero también las caídas en la negatividad sin esperanza. Se le pide que se mantenga, como debería mantenerse toda la Iglesia, en unión con el Crucificado, "el acontecimiento de la caída de los dioses» (Karl Rahner). Respecto a la sed de totalidad de la razón modema se le pide que pruebe ante todo la más breve definición de religión: «interrupción» (Johannes Baptist Metz). Frente a la nostalgia por el Otro, parece perfilarse la exigencia de una teología que narre, que hable de Dios contando el amor que nos ha manifestado en Jesucristo y que piense ese amor más grande con la discreción de la analogía; se trata de una teología fuertemente anti-ideológica que recuerde el proverbio hebreo: «El hombre piensa y Dios ríe», y que esté atenta por eso mismo a pensar sólo en lo que se necesita para suscitar en Él una sonrisa...

\section{Teología desde el reverso de la historia}

a) La «aldea global» que es el mundo en que estamos puede observarse desde otro punto de vista, distinto del de la parábola del hombre adulto que ha producido el proceso de emancipación y que ha sido llevada por él a las contradicciones sin salida de la modernidad. Este otro punto de vista es el del pobre, el del oprimido. Frente a una historia enten- 
dida como progreso, que margina y desprecia la historia de los vencidos, el reverso de la historia (Gustavo Gutiérrez) está cargado de la memoria de los oprimidos, borrada o reprimida demasiadas veces, de su presente de dolor, de lucha y de esperanza, del sueño de su futuro. El sujeto de esta otra historia es el otro: no ya el burgués que está tras la ideología liberal o tras la ideología de la revolución, sino el conjunto de las no-personas, las clases explotadas, las razas marginadas, las culturas oprimidas y despreciadas. Su interlocutor no es el espíritu moderno, ni la razón adulta, sino la enorme situación de miseria en que vive la mayor parte de la humanidad, los «subterráneos» del mundo, la suma infinita de historias de sufrimiento humano. En esos «bajos fondos», no menos que en el alto y agrietado edificio de la modernidad y de su larga cola que es la posmodernidad, es donde está llamada a situarse la teología cristiana. Y ello no con una decisión tomada en el despacho, en una especie de diálogo intelectual, sin compromisos y sin pasiones, sino estando dentro, en el corazón de esa historia, como acto segundo en relación con la primacía de lo vivido. La teología desde el reverso de la historia viene después de la mística y de la práctica del compartir: a Dios, en primer lugar, se le contempla al mismo tiempo que se pone en práctica su voluntad, su reino; solamente después se piensa en El.

Las raíces profundas de esta teología desde el reverso de la historia se pueden encontrar en la gran mística española del «siglo de Oro» (Teresa de Jesús, Juan de la Cruz, Ignacio de Loyola). A través de la piedad popular, que valora el corazón, la intuición y el recurso a las formas sencillas, pero profundamente contemplativas, de oración repetitiva y litánica, a través de la devoción a la pasión del Señor, que se expresa en formas densas e impresionantes y que alimenta la capacidad de aceptar los sufrimientos en compañía con el Crucificado, a través del sentido de la lucha y de la fiesta, que fomenta los itinerarios de penitencia, de conversión y de compromiso, y las explosiones colectivas del gozo por la salvación dada y recibida, se deja vislumbrar un sentido profundo de la presencia y de la acción de Dios en todos los aspectos de la vida. En las raíces de la mejor teología en la praxis de liberación asoma entonces algo muy distinto de una tierra extraña y lejana para el alma cristiana; en profundidad está el encuentro con el Absoluto y con la historia que proclama el evangelio en Jesucristo y la asimilación de este encuentro, tal como se realizó en las grandes figuras de los espirituales españoles, que influyeron fuertemente en las vicisitudes de su tiempo, alimentando una búsqueda y un deseo de Dios, que no llevan fuera de la historia, sino a la brecha, no a la soledad de un intimismo egoísta, sino a la compañía de los pobres y de los crucificados de este mundo. 
b) Estas raíces, próximas y remotas, filtradas a través del grito y de la oración de los pobres, llegan a dar fruto bajo el impulso del anhelo inextinguible de justicia, del que está cargada la situación del «reverso de la historia». Va surgiendo una nueva conciencia de la fe: la pobreza no es un simple vicio que haya que curar con la piedad de un asistencialismo benévolo, ni se trata de un mero retraso que exija un reformismo, en donde el pobre no es más que objeto de una acción que baje de arriba. La pobreza es fruto del sistema injusto de dependencia que liga al centro y a la periferia del mundo: el pobre -el negro, el indio, la mujer, el humillado y el ofendido del sentimiento popular- es el hijo de Dios desfigurado. No basta con prestarles una asistencia según un modelo de desarrollo, proyectado y gestionado por otros a su medida y según sus intereses: la crisis del «desarrollismo», que había inspirado también las relaciones entre los países desarrollados y el llamado «tercer mundo», es un camino sin retorno. Se impone en toda la línea el análisis de las dependencias, suscitando una praxis compleja y diversificada, que pasa ante todo a través de la concienciación del pobre. El pobre se va haciendo sujeto de su propia historia; recupera la identidad de su memoria, que le hace percibir toda la inmensa dignidad de su dolor pasado, del dolor de los vencidos; lee con ojos nuevos el presente, descubriendo relaciones injustas de dependencia en donde antes veía tan sólo el fruto de la fatalidad o el precio de una antigua culpa de retraso, y proyecta pasos concretos y posibles de liberación.

Todo esto no se realiza más que lentamente, a costa de mucho dolor, en medio de renuncias y de caídas, de desilusiones y de falsas esperanzas, de fracasos y de muerte. Entonces la pregunta más profunda que se le plantea a la teología en la praxis liberadora se convierte en la de una apología del dolor inocente, la de un sentido que asentar y la de una buena nueva que anunciar, que motiven el compromiso a pesar de la dura permanencia de los desgarramientos: «¿De qué manera hablar de un Dios que se revela como amor en una realidad marcada por la pobreza y por la opresión? ¿Cómo anunciar el Dios de la vida a personas que sufren una muerte prematura e injusta? ¿Cómo reconocer el don gratuito de su amor y de su justicia desde el sufrimiento del inocente? ¿Con qué lenguaje decir a los que no son considerados como personas que son hijos e hijas de Dios?» (G. Gutiérrez, Hablar de Dios desde el sufrimiento del inocente, Salamanca 1982,18s). Quien eludiese el peso de estas preguntas, quien se resistiera a asumirlas y a asumir con ellas el mundo de miseria y de dolor que allí se expresa, quien no sintiera sim-patía por esta historia de liberación de tantos humillados y ofendidos, no podría comprender el sentido de una teología desde el reverso de la historia El mundo de las 
no-personas exige el abandono de toda epistemología racionalista, que se contente con reconciliaciones puramente ideales, en favor de una epistemología de sabor bíblico, en la que comprender signifique al mismo tiempo amar y comprometerse por los demás.

c) Esta teología que se arraiga en la memoria espiritual del pueblo pobre y oprimido, bajo el reto de sus gemidos presentes y de su sed de liberación, se nutre de silencio y de atención para hacerse palabra: silencio acogedor y receptivo ante el dolor de los últimos y atención religiosa a la palabra del Dios vivo; palabra provisional y creíble para señalar el camino. Este itinerario no puede realizarse más que junto con los demás, al lado de ellos y por ellos: la des-privatización del mensaje cristiano comienza en la teología liberadora por el propio sujeto de la misma, que es el teólogo intensamente inserto en la vida de la comunidad y en la historia del pueblo. Sólo así es como puede llevar a cabo aquella confrontación de dos memorias -la memoria de la gente oprimida y la memoria «peligrosa» de la fe cristiana- en que consiste sobre todo su tarea. La fidelidad al mundo de los pobres, con todo el peso de sus limitaciones, viene a unirse con la fidelidad al mundo de Dios, a su revelación histórica, criterio de orientación, de juicio y de consolación, para trasladar el futuro de Dios al presente de los hombres y transformarlo con eficacia

Este itinerario de elaboración teológica, alimentado de la vivencia y de la acogida de la palabra de Dios en la compañía de la vida y de la fe, no está evidentemente libre de riesgos. Estos se presentan en cada uno de los momentos del camino. Si en principio está la praxis, ¿no se corre el riesgo permanente y sutil de reducir toda la reflexión a una lectura puramente sociológica y política de la realidad, sobre todo cuando ésta se presenta con esos dramas y con esos problemas que casi llegan a aplastar la posibilidad de una mirada dirigida al Otro? Si el criterio es la $\mathrm{Pa}-$ labra, ¿no se corre el riesgo de querer hacer que funcione demasiado, para dar explicaciones baratas y traicionar a aquella «inactualidad» que es al mismo tiempo un aspecto de la verdad que no se deja aprisionar en esquemas funcionales e ideológicos? Y finalmente, si se vuelve a la praxis, primera y última palabra del recorrido de la reflexión, ¿no se corre el riesgo de que todo quede absorbido por ella, en los resultados alcanzados o buscados, en un eficacismo que lo mide todo por el parámetro del éxito y no por el de la cruz, y que hace incomunicable la palabra alcanzada con formas y situaciones diversas? Son los mismos mejores artífices de la teología liberadora los que señalan estas posibles tentaciones: olvido de las raíces místicas, inflación del aspecto político, subordinación del discurso de fe al discurso de la sociedad, absolutizaciones indebidas, acentuación de las rupturas, cerrazón al diálogo de la comunión eclesial... 
Sin embargo, todo esto no impide que la teología desde el reverso de la historia tenga un sentido y esté llena de promesas, porque tiene en cuenta la condición de éxodo del vivir y del morir humano, no ya en abstracto, sino en la concreción de las humildes historias de los vencidos, de los que no tienen futuro, de los humillados y oprimidos. En este sentido la palabra de la fe en esta teología viene a situarse en medio de la aldea, en el corazón de la otra historia, que el Dios cristiano demuestra en su cruz haber privilegiado y hecho suya. Teología situada en la verdad del éxodo, no por eso se muestra menos fiel al adviento: la Palabra resuena en ella no como extraña y lejana, sino como familiar y cercana, capaz de dar sentido al compromiso y de contagiar la esperanza, realizando de este modo la promesa divina. Entre el éxodo y el adviento, entre el camino de los pobres hacia la tierra prometida y el don divino que viene a rescatar y a salvar la historia, la teología liberadora es mediación crítica, comprometiendo el pensamiento y la vida. Les devuelve la memoria a los humillados y oprimidos, alimenta la compañía del compromiso, contagia la esperanza. Les devuelve a los sin-futuro la capacidad de soñar: «Dichosos los que sueñan, porque llevarán la esperanza a muchos corazones y correrán el dulce riesgo de ver realizado su sueño» (Helder Cámara). Palabra provisional, camino que tendrá tanto mayor fuerza y significado cuanto más sepa seguir siendo fiel al Dios vivo y a la historia real. ¿Quién podrá sentir que ha llegado a la meta, mientras sea tan inmenso el pueblo de los oprimidos y parezca tan inconsolable su miseria? ¿Quién podrá decir que ha encontrado la respuesta exhaustiva y final a la acuciante pregunta del salmo: «¿Cómo cantaremos los cantos del Señor en tierra extranjera?» (Sal 137,4).

Una leyenda rabínica habla de un río en tierras lejanas, de un río tan piadoso que durante el sábado dejaba de correr: «Si en vez del Main -apunta Martin Buber- ese río pasase por Frankfurt, seguramente todos los judíos de Frankfurt observarían escrupulosamente el sábado. Pero Dios no realiza esos signos. Él siente un horror manifiesto de sus consecuencias inevitables, o sea, de que en ese caso serían precisamente los menos libres, los tímidos y los mezquinos los que se harían más piadosos. Y es evidente que Dios sólo quiere para sí a los hombres libres». A la teología no se le pide violentar la libertad de las conciencias con alardes de fuerza. Tampoco se le pide que se sienta segura, porque nada separa tan completamente al hombre de Dios como una piedad que esté segura de sí misma. A la teología se le pide que hable de Dios como humilde sierva, 


\section{Bruno Forte}

688

que tienda hacia Él como peregrina hacia la luz, guiada por la estrella de la redención que apareció en la noche de los tiempos, sin seducciones de cumplimiento o de posesión. En el Norte, como en el Sur del mundo, frente a la aldea posmoderna, como frente al reverso de la historia, a la teología se le pide de seguir viviendo la doble y única fidelidad, al tiempo y al Eterno, al presente de los hombres y al mañana de Dios, en la compañía del pueblo elegido por el Señor para ser en medio de los pueblos la Iglesia del amor, la comunidad de la esperanza más fuerte que el dolor y la muerte. 